\title{
Reflexión sobre el papel de los actores en el conflicto armado en Colombia y la importancia de la memoria histórica para la construcción de paz
}

\author{
David Ernesto Bautista-Erazo* \\ (davidbautistaqf@gmail.com)
}

Artículo de revisión recibido el 02/10/2015 y aprobado el 19/11/2015.

Cómo citar este artículo:

BAUTISTA-ERAZO, David Ernesto (2015). "Reflexión sobre el papel de los actores en el conflicto armado en Colombia y la importancia de la memoria histórica para la construcción de paz". En: Trans-pasando Fronteras, Núm. 8, pp. 67-83. Cali, Colombia: Centro de Estudios Interdisciplinarios, Jurídicos, Sociales y Humanistas (CIES), Facultad de Derecho y Ciencias sociales, Universidad Icesi.

DOI: $10.18046 /$ retf.i8.2086

\section{Resumen}

El conflicto armado en Colombia es único en su clase y su complejidad se puede entender haciendo un análisis de contexto histórico a través de una recapitulación de procesos de origen, expansión y degradación. Esta guerra se encuentra actualmente degradada: ni el Estado ni los insurgentes han podido alcanzar sus objetivos siguiendo una vía militar, al contrario, sólo se ha afectado el desarrollo humano y se han obstruido las opciones de las personas y sus comunidades. En este sentido, los daños e impactos de la guerra han sido profundos, especialmente en los habitantes de la periferia. Este texto tuvo como objetivo realizar una contextualización histórica que desembocara en mostrar que el conflicto

\footnotetext{
* $\quad$ Estudiante de Química Farmaceútica y Química de la Universidad Icesi
} 
armado en Colombia concierne, atañe, afecta e interesa a diversos grupos y que las afectaciones, daños e impactos han sido innumerables. Así, se estudió el papel del Estado y del gobierno, de las Fuerzas Militares, de los insurgentes, de las víctimas, de las minorías en estado de indefensión, de las organizaciones humanitarias y de los sectores internacional y económico en la dinámica del conflicto. También, se mostró que el grueso de personas que no sufre directamente la guerra son aquellas que deben ser sensibilizadas pues son las que tienen el poder de sobrellevar el posconflicto con una construcción de paz efectiva. Finalmente, se comentó sobre el papel de la memoria histórica y los testimonios que se recogen como un recordatorio. Ambos sirven como una alarma o aviso de lo crudo que puede llegar a ser el hombre frente a sus congéneres y por tanto se recalcó su verdadera importancia para dirigirse al perdón y reconciliación y para entender que se deben rescatar diversos valores para que el posconflicto sea fructífero y que la paz lograda sea estable y duradera.

\section{Palabras clave}

conflicto armado, construcción de paz, víctimas, memoria histórica, posconflicto

\section{Contexto: origen, expansión y degradación del conflicto armado en Colombia}

El conflicto armado en Colombia es sui géneris y, por tanto, para entender su complejidad, es importante recapitular los factores determinantes y recurrentes que dieron origen al mismo y que aún lo siguen nutriendo y degradando. El objetivo de esta sección es contextualizar sobre las diferentes etapas que, históricamente, ha seguido el conflicto armado en Colombia, a saber: origen, expansión y degradación.

Las hipótesis del origen del conflicto corresponden a que existe: (1) ausencia del Estado en una periferia ${ }^{1}$ con espacio para creación de ejércitos no estatales y (2) un Frente Nacional que solucionó políticamente La Violencia mas dejó remanentes de guerrillas ensañadas en el seno del conflicto social que finalmente se organizaron desde una resistencia campesina hasta emprender un proyecto de revolución. Las hipótesis anteriores se pueden agrupar como sigue: el 'problema de la tierra' -estructuración del territorio- en Colombia y la exclusión política, sumado a una periferia con profundos problemas sociales, da origen y nutre al conflicto armado en Colombia. No obstante, a pesar de que el conflicto se ensañe en la periferia, es "el centro" el objetivo de dicho conflicto pues es allí donde está el poder político (PNUD, 2003).

1 La periferia se refiere a lugares o zonas de colonización con baja integración al mercado, menos poder político, y alta discriminación que afecta el campesinado en estado de marginalidad. 
El 'problema de la tierra', que ha estado presente en la historia de Colombia y que es una de las principales causas del conflicto, surge debido a que este país está geográficamente accidentado y es económicamente agrícola. La colonización desregular en los diversos márgenes da lugar a fronteras entre el centro y la periferia con economías peculiares. Así, las modalidades de explotación: minifundios y latifundios (Meló, 1990:10), sumadas a la ausencia del Estado en las zonas marginales, pueden dar lugar a un campesinado con problemas sociales y económicos que ensañan un conflicto social latente (PNUD, 2003; Uribe, 1997).

Por otra parte, la exclusión social, que ha vivido Colombia desde su organización política bipartidista, estalló en La Violencia. A pesar de que la amnistía de Pinilla y el Frente Nacional pongan fin a esta problemática política, sigue existiendo una dificultad de orden social estructural que afecta principalmente a la periferia y que termina fomentando la aparición de guerrillas que pasan de ser una resistencia campesina a un bandolerismo revolucionario. Por otro lado, La Violencia no sólo generó guerra política, sino también malestar, desigualdad, injusticia, y demás inequidades que afectaron profundamente la zona periférica (PNUD, 2003). En este sentido, La Violencia procede en el centro político pero se expresa en la periferia, y por ende, su finalización aleja al conflicto del centro pues la exclusión bipartidista lanza a las guerrillas, que "les toca jugar a ser ejércitos y no partidos políticos" (Zuluaga, 1995:129), a una guerra prolongada por el poder pero cuyas acciones violentas atacan principalmente las zonas marginales (lucha armada en el campo).

La expansión del conflicto ha sido heterogénea (difícil de precisar el cuándo y el dónde) pues cada región tiene diferentes grados de permeabilidad gracias a las particularidades geográficas, económicas y sociales. En este sentido, se han estudiado tres aspectos determinantes de dicha expansión: la estrategia de la guerrilla y los paramilitares, la permeabilidad de la región y la lucha por las rentas (PNUD, 2003:65-77).

En cuanto a la permeabilidad de la región se puede mencionar que obedece a una dinámica de oferta y demanda. La oferta se refiere a seguridad, administración de la justicia, infraestructura, cultura y resonancia ideológica, movilización ciudadana y aval de lo ilegal. En cuanto a la demanda, esta puede ser económica (organización territorial) y social (derecho de propiedad y cuestiones comerciales y del trabajo). En general, la 
guerra en Colombia inicia por el control de tierras y se desplaza al control de las rentas, es decir, el conflicto armado tiene su origen debido a una problemática tanto agraria como de exclusión política y social, y posteriormente se transforma en una lucha o carrera por conseguir riqueza y aprovecharse de las bonanzas en la periferia (PNUD, 2003). Es sabido que sitios de bonanza (agro, minería y recursos) son lugares propicios para el conflicto social que nutren y alargan el conflicto; en este sentido, el conflicto armado cuenta con un catalizador muy importante que es el narcotráfico, el cual mueve dinero para los diversos actores armados.

En la degradación del conflicto se debe analizar el fracaso tanto del Estado como de las acciones guerrilleras para entender por qué esta guerra es un "conflicto de perdedores" (PNUD, 2003). Primero, el fracaso del Estado colombiano se debe principalmente a (1) que no tiene presencia en la periferia, lo que facilita el surgimiento de ejércitos privados como los paramilitares, y también a (2) que los derechos de propiedad y respeto a contratos (justicia) están ausentes. Los paramilitares son grupos armados que nacen de dos causas específicas: el desespero y la codicia; inicialmente protegían de la insurgencia a los empresarios influyentes pero después se agruparon para coaccionar violentamente (PNUD, 2003:59). Respecto a la ausencia de justicia, se puede decir que propicia los conflictos, la inestabilidad y la incertidumbre y sirve como semilla para la conflictividad, la arbitrariedad y la vulnerabilidad que finalizan en la creación de dichos ejércitos no estatales (PNUD, 2003; Nozick, 1974).

Por otra parte, las acciones gubernamentales frente a los insurgentes son principalmente militares y, por tanto, el conflicto se ha extendido por décadas, pues es claro que la salida a este conflicto no es militar ya que la causa es una problemática social. Así, el conflicto se ha prolongado pues no se ha abordado su solución de manera prioritaria, integral, concertada y comprendiendo sus causas. En general, las razones estructurales del fracaso estatal comprenden una condición geográfica compleja, exclusión política y social (Frente Nacional y pobreza, por ejemplo), desarticulación de las élites (que son clientelistas, cortoplacistas y facilistas) y, finalmente, el narcotráfico que cataliza todo el sistema (PNUD, 2003).

Sin embargo, también existe un fracaso de la insurgencia, pues sus acciones violentas no han sido lo suficientemente atroces y efectivas como para tocar el centro y 
tomarse el poder y sus organizaciones políticas siguen siendo excluidas (y, de hecho, rechazadas democráticamente por la población colombiana). Por tanto, a pesar de que el centro es el origen y el objetivo del conflicto, permanece sin ser realmente tocado por la guerrilla (PNUD, 2003).

Finalmente, es importante comprender que el conflicto armado en Colombia no es completamente campesino, también toca el centro de maneras violentas y complejas; no está totalmente ignorado por las élites y el gobierno, a pesar de sus decisiones erradas; ni tampoco es solamente periférico pues el objetivo político es el centro (PNUD, 2003:43). A pesar del origen que obedece tanto a problemáticas agrarias como de exclusión sociopolítica, el conflicto se degrada a una lucha por conseguir riqueza y por aprovecharse de las bonanzas: transformación de la territorialización al rentismo. La degradación de este conflicto peculiar, extremadamente largo, sui géneris y sin sentido obedece a las siguientes lógicas que se alimentan y entrelazan: militarización, ya que se favorece la vía armada sobre la vía política; rentismo, porque las convicciones se desplazan por el afán de lucro; territorialización, donde prima el establecimiento y manutención en el control sobre determinados territorios; terror, que incluye limpieza inicial, soberanía jurídica, dilema de seguridad, guerra contra los civiles y ataques a infraestructura nacional; criminalización, ya que abundan los crímenes corrientes cometidos por miembros de los cuerpos armados y, por último, vinculación apolítica, pues los motivos para estar en la guerra son tan degradados como la guerra misma (PNUD, 2003:76). Ergo, es evidente que este conflicto se ha convertido en una guerra de perdedores la cual ha mancillado profundamente el desarrollo individual y colectivo de la población colombiana.

\section{A quiénes concierne esta guerra: reflexión sobre el papel de los diversos actores}

Este conflicto, al sufrir las diversas lógicas de degradación, afecta el desarrollo humano pues obstruye las opciones de las personas como individuos y resquebraja el desarrollo del país en diversos ámbitos como el económico, social, político y de integración. Por tanto, los daños e impactos del conflicto sobre el desarrollo de Colombia han sido profundos, graves y negativos; en este sentido, la guerra ha desviado el curso de la vida de muchos civiles y sus familias y ha estropeado el desarrollo humano al limitar las opciones de una gran parte de la sociedad (PNUD, 2003:99). En general, dado que el 
conflicto armado se ensaña en la periferia, muchas de las personas que han sido afectadas profundamente tanto moral, emocional, sicológica, política y socioculturalmente son aquellas que por sus mismas condiciones de vida son más susceptibles a los achaques de la situación. Así, campesinos, minorías sistemáticamente discriminadas (afrodescendientes, indígenas, población LGTBI, etc.) y otros grupos como mujeres, niños y ancianos han sobrellevado los mayores impactos negativos de este conflicto; inmediatamente, se piensa que el conflicto concierne sólo a los actores armados y a las víctimas directas.

Sin embargo, la injusticia del conflicto armado en Colombia no sólo afecta a las víctimas. Además de la población vulnerable que vive en la periferia y que sufre los ataques denigrantes de los diversos grupos armados (guerrilleros, paramilitares y Fuerzas Armadas), existen otros tipos de personas y sectores a los cuales el conflicto toca de distintas maneras. El objetivo de esta sección es argumentar por qué el conflicto armado en Colombia concierne, atañe, afecta e interesa a variados grupos y por qué es necesario reflexionar acerca de la urgencia de una salida dialogada a esta guerra absurda, ilógica e irracional.

Inicialmente, una visión simplista del conflicto lleva a pensar que son los políticos y sus gobiernos de turno quienes tienen la responsabilidad de terminar "con mano dura" el conflicto; son ellos quienes deberían poner toda su "fuerza militar" para derrotar a la guerrilla. Sin embargo, como se ha reiterado, esta guerra no tiene una salida militar pues sus causas son principalmente problemáticas sociopolíticas. De hecho, el fracaso del Estado colombiano es entendido desde que no presta atención al devenir que ocurre más allá de la frontera centro-periferia, lo que facilita la progresión de insurgencia y la violación de derechos colectivos que mantienen cohesión social, verbigracia, los contratos; consecuentemente, la ausencia de justicia propicia las riñas y la inconformidad (PNUD, 2003). Por tanto, se ha fracasado en la terminación de la guerra debido a que no ha existido un plan prioritario e integral que tenga en cuenta diversos aspectos anteriormente mencionados como el 'problema de la tierra' y la participación política. Este panorama se agrava al entender que Colombia es un país heterogéneo geográfica y socialmente y que sus gobiernos no han sido más que excluyentes y facilistas (Revista Semana, 2000), preocupados sólo por los votos y acompañados de corrupción. Adicionalmente, el narcotráfico ha aumentado progresivamente y ha permeado todas las esferas de actuación, catalizando negativamente el conflicto en pro de su degradación. 
Así, la mentalidad de actuación gubernamental debe tomar un giro que vaya de las armas a la discusión; grosso modo, el papel del gobierno va a tener que ser el de ente dialogador que disponga toda su maquinaria constitucional para alcanzar un proceso de paz que resuelva las causas del conflicto, acabe con la insurgencia y que proteja a las víctimas, mientras genera justicia con un marco legal, social y educativo adecuado y efectivo. La guerra concierne al gobierno porque son los políticos los que tienen el deber de garantizar que los colombianos disfruten de un desarrollo humano pleno en el marco de la protección de los derechos humanos fundamentales expuestos en el catálogo de la Constitución. Por tanto, para el Estado colombiano y su Constitución es ilógico que una guerra rompa con los usufructos a los que deberían acceder todos los ciudadanos que gozan del principio de principios: la dignidad. Además, en términos prácticos, son los políticos quienes enfrentan la crítica y las miradas de las veedurías nacionales e internacionales así como los posibles detrimentos a su popularidad.

Por otra parte, el gobierno actúa mediante las Fuerzas Militares. En teoría, son los grupos armados legales los únicos que tienen poder para hacer cumplir las normas por medio del uso de violencia. Sin embargo, su trabajo se ha sobredimensionado de manera tal que, antes que proteger la población civil, se han convertido en otro actor armado más que restringe la libre movilidad y economía y el libre desarrollo de las ideologías de los campesinos y minorías, y que, además, comete actos de lesa humanidad para maquillar su ineficiencia (por ejemplo, los "falsos positivos"). La guerra concierne a este grupo porque sencillamente lo primero es la razón de ser de lo segundo: para el Estado y sus ramas de acción militar, la guerra se ha convertido en un negocio; las Fuerzas Militares son una extensión seudolegal corrupta que durante su ejercicio, incluso, propicia la aparición de ejércitos paralelos que se encargan de los actos de crueldad. Sin embargo, pese a que las Fuerzas Militares sí han ejercido diversos actos "legítimos" en contra de la violencia "política" de los actores armados ilegales, es probable que dichos actos carezcan de sentido dadas las condiciones geográficas, sociales, económicas y de degradación que sufre este conflicto (PNUD, 2003:39). Por tanto, es menester concluir que debe existir: regulación más eficiente en cuanto a las acciones y replanteamiento de objetivos para que estén acordes con una realidad tal que beneficie a la población que supuestamente deben proteger. 
Por supuesto, el conflicto armado también concierne a los insurgentes. A las guerrillas o paramilitares, dada la vinculación tremendamente apolítica que existe, ingresan muchas personas en busca de venganza, poder, dinero, sentido de vida, etc. Esta heterogeneidad y cantidad de individuos armados ha ocasionado que no haya ni un objetivo político ni racionalidad en las acciones armadas - son actos guiados meramente por la violencia. Dado que a los actores armados ilegales les toca "jugar a ser ejércitos y no partidos políticos" (Zuluaga, 1995:129), se ha ensañado una guerra prolongada por el poder cuyas acciones violentas afectan principalmente a personas inocentes en estado de indefensión y que viven en zonas marginales con poco acceso estatal. En general, es evidente que la guerra sucia entre guerrilleros y paramilitares lo único que ha logrado, a través de las últimas décadas, es dejar pueblos y familias masacradas, violadas, desplazadas, desaparecidas y en la ruina. Así como el Estado ha fracasado, estos actores armados ilegales también se pueden entender como perdedores: sus acciones violentas, con toda su atrocidad y horror, aún no aquejan el centro; de hecho, lo único que han ocasionado es que se vean como criminales más que como actores políticos.

Después de hablar de los actores armados - que son quienes hacen la guerra-, el grupo principal al que concierne el conflicto - en cuanto a que sus impactos son profundamente negativos-corresponde a las víctimas y sus familias. Es difícil comprender cómo un conflicto armado que surge con la ideología de luchar por los derechos de los campesinos y de los trabajadores se volcó hacia un conflicto que destruye las oportunidades de los más susceptibles. Sin embargo, una vez se tiene en cuenta que el conflicto entre más largo e irresoluto más se degrada, entonces se puede entender por qué son los habitantes de la periferia quienes sufren con alta intensidad las afectaciones.

Estos impactos son complejos desde que influyen muchos factores como el tipo de victimario, el carácter del evento, las modalidades de violencia, los perfiles de la víctima, sus condiciones socioeconómicas y demográficas, el tipo de apoyo recibido, la respuesta social y las acciones u omisiones del Estado. En Colombia, las víctimas directas han experimentado el horror extremo en condiciones de enorme indefensión y humillaciones (Grupo de Memoria Histórica, 2013). A ellas concierne la guerra en cuanto esta les ha destruido toda posibilidad de desarrollarse como humanos, de vivir dignamente (como quiera, con lo que quiera y bien) y de proyectarse al futuro con sus familias y 
comunidades. Además, la guerra ha "cambiado los sentimientos, los pensamientos y los comportamientos de las personas" (Grupo de Memoria Histórica, 2013:288) pues son los hechos violentos los que rompen con el curso de las vidas de las personas que viven en la periferia porque arrebatan la percepción del mundo y degradan las creencias, relaciones y todos aquellos aspectos que soportan la existencia y el curso de las actividades que permiten a un ser humano desarrollarse como tal (Grupo de Memoria Histórica, 2013).

Son las víctimas de la violencia a quienes se les desestructuran las familias, se les destierra de lugares de existencia, se les ahuyenta de sus labores y se les priva del futuro. Son las víctimas las que sufren las heridas y las lesiones de enorme gravedad que conllevan consecuencias negativas y definitivas que muchas veces se constituyen como la manifestación más evidente y, aún así, más ignorada del impacto de la guerra. Además, a ellas concierne la guerra en cuanto a que la impunidad, la falta de justicia y el rechazo social aumentan su frustración y desgaste ocasionando procesos de empobrecimiento y revictimización (Grupo de Memoria Histórica, 2013).

En este sentido, la guerra ha afectado profunda y especialmente a las minorías ${ }^{2}$. Estas son víctimas singulares pues, además de sufrir las injusticias de los actores armados, también son sistemáticamente discriminados por el resto de la sociedad. Así, cuando son desplazados, extorsionados, secuestrados, masacrados y mancillados, antes que encontrar apoyo y refugio en el gobierno y en la sociedad, generalmente hallan procedimientos judiciales infructuosos, rechazo, incomprensión e impunidad que, muchas veces, agudiza más su estado de indefensión. A las minorías concierne la guerra desde que se merecen y tienen el derecho a ser tratados en igualdad de condiciones y es dicho conflicto el proceso que más violaciones a este principio conlleva. En general, la guerra les ha ocasionado desplazamiento, amenaza, intimidación, enfrentamientos, tensión, angustia, padecimiento, miedo, penuria económica, hacinamiento, estigmatización, discriminación y maltrato (Grupo de Memoria Histórica, 2013).

El conflicto también concierne a la comunidad internacional. Los intereses de las potencias del norte y el miedo de los vecinos son factores que afectan las políticas adoptadas por el gobierno colombiano en diversas materias. Primero, las potencias piden

2 Afrodescendientes, indígenas, población LGTBI, mujeres, niños, ancianos, líderes comunitarios, sindicalistas, ecologistas, etc. 
control al narcotráfico, protección de los derechos humanos y un clima de inversiones positivo. Por otra parte, a los vecinos les preocupa que en sus fronteras ocurran procesos criminales como secuestros, extorsiones, desplazamientos, ataques, etc. Así pues, el conflicto toca las relaciones internacionales de Colombia de manera negativa ya que se genera tensión y presión y, al mismo tiempo, se aleja la inversión y el turismo. Esta imagen negativa internacional ha frenado el crecimiento económico que podría haber tenido Colombia de otra manera.

Para las ONG, la Misión Médica, la Cruz Roja, la Iglesia Católica y demás organizaciones sin ánimo de lucro que luchan porque los seres humanos vivan dignamente, el conflicto armado es una guerra que afecta en diversos niveles tal objetivo. Para estos sectores, la guerra en este país es fuente interminable de oportunidades de intervención pues día a día se cometen crímenes que afectan la salud y la vida de los colombianos, principalmente los que habitan en la periferia. La Cruz Roja media, por ejemplo, la liberación de secuestrados; Human Rights Watch, una ONG que vigila los derechos humanos, se preocupa porque los crímenes de lesa humanidad cometidos por los diversos actores no queden impunes ante la justicia y otros, como la Unicef, invierten esfuerzos para que los niños no sean reclutados y dejen de estudiar. Como estos casos, existen muchas otras organizaciones tanto gubernamentales como no gubernamentales que ponen empeño en proteger y reparar a la población más violentada. Por otra parte, es de interés para los ecologistas y la comunidad en general el hecho de que los actores armados incurran en prácticas que afectan el medio ambiente como: voladura de oleoductos que contaminan los cuerpos de agua, tala indiscriminada, extracción ilegal de minerales, invasión de reservas naturales y fomento en la extinción de especies de fauna y flora (Grupo de Memoria Histórica, 2013: 277).

Otro sector afectado por la guerra es el económico. Tanto para empresas multinacionales como para miniempresas familiares, el conflicto armado ha afectado la inversión extranjera, ha causado inseguridad en el consumidor, ha generado inestabilidad en los precios y no ha permitido un óptimo desarrollo de sectores de gran oportunidad de crecimiento. Así pues, a los empresarios les interesa la guerra desde que sus oportunidades de lucrarse se han visto truncadas en diferentes niveles. También se debe hablar de las empresas ilegales: al entender que el narcotráfico es el 
catalizador de esta guerra absurda, se analiza que a los carteles, las 'bacrim'” y los productores de drogas, por el contrario, les interesa que este conflicto se prolongue ya que se ha constituido en su modus vivendi.

Por otra parte, un gran sector de la población colombiana no comprende el conflicto armado. A muchos no les interesa pues no los "afecta", a otros les parece atroz pero no generan acciones y tienen una visión simplista, otros no conocen ni la historia ni la naturaleza del conflicto ni se preocupan por saberlo y otros, muy pocos, trabajan desde algún ámbito, por pequeño que fuere, para lograr que Colombia tenga un ambiente más justo en el que las opciones se puedan desarrollar tanto individual como colectivamente. Es en esta franja de población que la guerra no toca directamente, que se ha constituido el principal sector que debe ser sensibilizado frente a las injusticias y el sinsentido del conflicto pues son estas personas las que tienen una posibilidad, dadas sus condiciones y visibilidad, de generar un cambio por medio de la acción política y popular. No es cierto que el conflicto no toque a la población que vive en las ciudades pues el desarrollo económico y sociocultural de todo el país se ve afectado y comprometido en múltiples niveles por las acciones insurgentes que ocurren en la periferia.

Es importante romper el esquema, el estereotipo o el precepto de que el conflicto es blanco y negro, que hay "buenos" y "malos", que es un problema de los que viven en el campo, que los ataques se ven por televisión a pesar de que pasen a unos kilómetros de distancia y que la guerrilla se acaba con mano dura y con "bala en el monte". El conflicto tiene que ver con todos nosotros, desde las víctimas directas y los actores que viven los hot spots y los procesos de desplazamiento y muerte, hasta las élites, la población urbana y la comunidad internacional que miran de reojo la guerra y que sólo prestan atención cuando un evento se vuelve mediático. No es lógico extender esta guerra injusta que sólo trae afectaciones al desarrollo humano individual y colectivo, que rompe con las oportunidades de vida de las personas, que no permite el progreso en el campo y las ciudades, que solamente enriquece a los poderosos (sean legales o ilegales) y que daña la imagen internacional vital para los procesos de comercio exterior y globalización. 
Finalmente, es importante reflexionar sobre el daño que se causa sobre toda la población sin importar raza, género, nivel socioeconómico, modo de vida, cultura, creencias, profesión, etc. Las conclusiones obtenidas deben servir para poder actuar a favor de la protección de víctimas; por tanto, es importante conocer el papel de cada actor armado y no armado en la guerra; de manera que se incluyan todos los grupos de colombianos y extranjeros que se relacionan indirectamente a favor y en contra de este conflicto. En otras palabras, a pesar de que el absurdo de la guerra sea tan evidente, gran parte de la población es indiferente frente a la situación de horror que sucede; por tanto, es hora de comprender que el conflicto armado en Colombia, que nos toca en diferentes niveles, necesita un punto final y que después de esto se debe garantizar que existan espacios efectivos donde se desarrolle la justicia, la conciliación y la reparación que la población vulnerable ha reclamado desde hace décadas.

\section{La importancia de los testimonios de las víctimas y la memoria histórica en el escenario del posconflicto y la construcción de paz}

Tzvetan Todorov, en su frase "el mal sufrido debe inscribirse en la memoria colectiva, pero para dar una nueva oportunidad al porvenir", argumenta que la memoria es necesaria para poder construir paz. Así, similar a los testimonios que brindaron los sobrevivientes del Holocausto, como Primo Levi , es la recopilación de memorias en el caso colombiano; por ejemplo, la que hace el informe ¡Basta Ya! (Grupo de Memoria Histórica, 2013). En el caso de Primo Levi, él explica que su deber como testigo del terror del Tercer Reich es contar cómo vivió en los campos de concentración para que la humanidad comprenda que es una etapa que no debe volver a repetirse (Levi, 1958) a causa de la sevicia de sus procesos de deshumanización y automatización de la "espontaneidad humana" (Arendt, 1998). En otras palabras, las memorias en tiempos de conflicto no se recolectan para obedecer alguna mecánica sinsentido; au contraire, se recogen como un recordatorio, una alarma, un aviso, de lo crudo que puede llegar a ser el hombre frente a sus congéneres. Por tanto, aúna el dolor y lo expone en el escenario público a manera de sensibilización, a manera de mecanismo para que la sociedad -que el conflicto no toca directamente- se espabile frente a la situación para vencer la cotidianización del conflicto. 
Sólo después de que toda una sociedad ha comprendido la profundidad de los daños e impactos causados por un conflicto tan largo y degradado y que en sus memorias se hallen impregnados no números ni cifras de muertos, secuestrados, crecimiento económico, etc., sino también testimonios de niños mutilados, de comunidades destruidas y de mujeres y hombres sin futuro, es que dicha sociedad va a poder darle espacio, con conciencia, a los procesos de construcción de paz. Así, es importante "tocar la llaga para que pueda sanar". Adicionalmente, para poder pasar a un capítulo más pacífico, es necesario "dejar las cuentas claras" y esto se puede lograr sólo con una conciliación basada en un acto de memoria ya que la verdad es importante para proceder hacia el perdón y la reconciliación. Esto no concierne sólo a las víctimas directas sino también a la población en general, pues somos todos quienes debemos generar procesos de reconstrucción de civismo en conjunto. Es precisamente a eso que se refiere Todorov con "dar la oportunidad de porvenir".

Al saber que la guerra toca todas las esferas de la sociedad colombiana, es importante romper los esquemas y preconceptos que se tienen frente a la misma: el conflicto sí tiene que ver con todos nosotros. Dadas las características de este conflicto, es importante reflexionar sobre el daño de diversa índole que se causa sobre toda la población y, por supuesto, se debe llevar a la generación de conclusiones para poder actuar a favor de toda la sociedad colombiana. Por lo tanto, la educación y la sensibilización en temas del conflicto son de vital importancia para sobrellevar los tiempos venideros en los que la ética, civismo y cultura van a ser los determinantes de que la paz sea duradera y sin interrupciones. Es importante, ergo, destruir la indiferencia que rodea el conflicto: es hora de generar espacios para comprender sus diversas temáticas y para recapitular y conocer sobre los hechos que han ocurrido (masacres, víctimas, daños medioambientales, política sucia, narcotráfico) y los que deben ocurrir a raíz de lo anterior (restitución, perdón, justicia transicional, no impunidad, construcción de ciudadanía). Los actuales dictámenes de "buenos y malos" y la somera crítica al Estado y a los actores armados enceguecen la oportunidad para reconocer y aplicar aspectos básicos de la construcción de paz: cultura, civismo, ciudadanía, tolerancia, respeto y solidaridad. Ya que de la carencia o tergiversación de los valores nacen conflictos, es importante generar sensibilización y educación en la población sobre las causas, proceso de evolución, efectos en diferentes esferas y posibles soluciones dialogadas a la guerra, con el objetivo de fomentar la construcción de paz. 
"Muchos quieren seguir viendo en la violencia actual una simple expresión delincuencial o de bandolerismo, y no una manifestación de problemas de fondo en la configuración de nuestro orden político y social" (Sánchez, 2013). Por ese motivo, estoy de acuerdo en que la construcción de paz en este país debe tener un abordaje maximalista a mediano-largo plazo pues es necesario que los problemas estructurales socioeconómicos y los problemas culturales-cívicos se superen con estrategias adecuadas y eficientes (Rettberg, 2003). Así, la Agenda para la Paz que se adelanta en La Habana está adecuada desde que: (1) recoge los problemas que dieron origen al conflicto (exclusión y tierras), (2) comprende problemáticas de catálisis (narcotráfico) y (3) entiende la situación de las víctimas (mesadeconversaciones.com.co, 2015).

"La memoria histórica es un recuerdo colectivo, una evocación volcada hacia el presente del valor simbólico de las acciones colectivas vividas por un pueblo en el pasado [...] La memoria histórica permite desmitificar los enfrentamientos del presente y buscar soluciones" (García-Bilbao, 2002). En el caso del Conflicto Armado en Colombia, la memoria histórica es importante para que las soluciones planteadas tengan un sentido integral que reconozca, desde diversos puntos de vista, lo sucedido y que involucren como fin la reconciliación de las partes. En este sentido, la ética de la memoria y la recapitulación de los estragos del Conflicto Armado deben servir como fundamento en la etapa de reconciliación y reparación que fomente la responsabilidad ciudadana frente al posconflicto pues la participación de la comunidad es decisiva al momento de que las estrategias de construcción de paz tengan un resultado efectivo e integral. Por otra parte, Sánchez (2013) explica que en Colombia la memoria no es precisamente una herramienta del posconflicto sino que surgió naturalmente en resistencia a la cotidianidad absurda de la muerte y destrucción que asola la periferia. La resistencia se convierte en memoria y así, en paralelo, se construye justicia al lado de un conflicto continuo. Por tanto, la memoria funciona además de recordatorio y fundamento de soluciones, como herramienta para la consecución de reparación de los inocentes que día a día viven el subyugo del horror.

En el caso colombiano, la memoria histórica, para muchos de los habitantes del centro, no consiste en hacer una reminiscencia del horror pasado, como se plantea formalmente en su definición. Parece ser que, debido a la cotidianización del conflicto y al hecho de que su horror se ensañe en la periferia, la memoria histórica tiene el rol de mos- 
trar y sensibilizar por primera vez a los habitantes que no han conseguido comprender que la guerra nos atañe a todos. Por tanto, la memoria histórica pasa a tener una función expositiva y educativa para la comunidad en general y, de esta manera, su importancia se incrementa, ya que la construcción de paz requiere del trabajo, la disposición y la mediación de todo el colectivo social.

No obstante, la memoria histórica colectiva debe utilizarse de manera racional ya que de emplearse inadecuadamente como parte del fundamento de las estrategias de construcción de paz puede llevar consigo a procesos de revictimización y nuevas vulneraciones de los derechos de las víctimas (Antequera Guzmán, 2011). Cuando se menciona que es necesario recordar para perdonar y reconciliar, parece ser importante tener en cuenta que el pasado y el horror aún viven en el presente de las víctimas y que, como tal, el tratamiento de la memoria debe realizarse con respeto y con una reconciliación sincera en la que prime la oportunidad de la víctima para ayudar a la sociedad en mostrar la degradación y fomentar la no repetición pero que al mismo tiempo se demanden sus propios derechos de reparación.

A manera de conclusión, es menester recalcar que la guerra no se refiere únicamente las balas y a la muerte; sino también a su problemática estructural de fondo: exclusión, miseria, falta de garantías y oportunidades, odio, intolerancia, irrespeto por a la diferencia y también a una misma degradación del amor por el prójimo y la cultura. Por tanto, la memoria es vital para recordarnos por qué es justo y necesario que Colombia ya empiece a pensar en la paz, paz que sea construida por todos para todos.

\section{Bibliografía}

ANTEQUERA GUZMÁN, José Darío. (2011). "Memoria histórica como relato emblemático: consideraciones en medio de la emergencia de políticas de memoria en Colombia." Tesis de Maestría. Pontificia Universidad Javeriana, Bogotá.

ARENDT, Hannah. (1998). Los orígenes del totalitarismo. (G. Solana, Trad.) Bogotá, Colombia: Taurus.

GRUPO DE MEMORIA HISTÓRICA. (2013). Los impactos y los daños causados por el conflicto armado en Colombia. En GMH, ¡BASTA YA! Colombia: Memorias de guerra y dignidad. (259-377). Bogotá, Colombia: Imprenta Nacional. 
LEVI, Primo. (1958). Se questo è un uomo. Turín, Italia: Giulio Einaudi Editore Torino.

MELÓ, Jorge Orlando. (1990). Prólogo. En A. Molano, Aguas arriba. Entre la coca y el oro. (177). Bogotá: El Áncora Editores.

NOZICK, Robert. (1974). Anarquía, Estado y utopía. México: Fondo de Cultura Económica.

PNUD. (2003). Daños al desarrollo: las opciones truncadas. En PNUD, \& M. Giraldo (Ed.), El conflicto, callejón con salida. Informe Nacional de Desarrollo Humano para Colombia-2003 (97-115). Bogotá, Colombia.

PNUD. (2003). Degradación: una guerra de perdedores. En PNUD, \& M. Giraldo (Ed.), El conflicto, callejón con salida. Informe Nacional de Desarrollo Humano para Colombia-2003 (78-95). Bogotá, Colombia.

PNUD. (2003). Expansión: la guerra en las regiones. En PNUD, \& M. Giraldo (Ed.), El conflicto, callejón con salida. Informe Nacional de Desarrollo Humano para Colombia-2003 (47-77). Bogotá, Colombia.

PNUD. (2003). Orígenes: guerra en la periferia. En PNUD, \& M. Giraldo (Ed.), El conflicto, callejón con salida. Informe Nacional de Desarrollo Humano para Colombia-2003 (18-45). Bogotá, Colombia.

RETTBERG, Angelika. (2003). Diseñar el futuro: una revisión de los dilemas de la construcción de paz para el posconflicto. En M. E. Cárdenas-Rivera, \& R. Romero-Ospina (Ed.), La construcción del posconflicto en Colombia. Enfoques desde la pluralidad (Primera ed., págs. 83-106). Bogotá, Colombia: Friedrich Ebert Stiftung en Colombia (FESCOL) y Fondo Editorial CEREC.

SÁNCHEZ, Gonzalo. (2013). Prólogo. En GMH, ¡BASTA YA! Colombia: Memorias de guerra y dignidad (13-16). Bogotá, Colombia: Imprenta Nacional.

URIBE, María Teresa. (1997). La negociación de los conflictos en el ámbito de viejas y nuevas sociabilidades. En Conflicto y contexto. Resolución alternativa de conflictos y contexto social (165-180). Bogotá: Tercer Mundo Editores/Instituto SER de Investigaciones/Colciencias.

ZULUAGA, Jaime. (1995). De guerrillas a movimientos políticos: análisis de la experiencia colombiana. En J. Guerrero, Iglesia, movimiento y partidos: política y violencia en la historia de Colombia (Vol. IV, págs. 125-134). Tunja, Colombia: Colección Memorias de Historia. 
Documentos de prensa

Revista Semana. "Muertos de la risa". Revista Semana. Bogotá, 2000.

\section{Linkografia}

GARCÍA-BILBAO, Pedro A. (2002). Sobre el concepto de memoria histórica. En: Sociología Crítica. Consultado el día 3 de febrero del 2016, desde https://dedona.files. wordpress.com/2010/01/scwp-05-garcia-bilbao.pdf

MESADECONVERSACIONES.COM.CO. (2015). "Acuerdo General de Terminación del Conflicto". Consultado el día 8 de septiembre de 2015, desde Mesa de Conversaciones para la terminación del conflicto y la construcción de una paz estable y duradera en Colombia: https://www.mesadeconversaciones.com.co/sites/default/files/ AcuerdoGeneralTerminacionConflicto.pdf 